\title{
Combating Hepatitis B: The Tripura Model
}

\author{
${ }^{1}$ Pradip Bhaumik, ${ }^{1}$ Ajit Ranjan Choudhury, ${ }^{2}$ Priyabrata Sinha \\ ${ }^{1}$ Department of Medicine, Agartala Government Medical College, Agartala, Tripura, India \\ ${ }^{2}$ IGM Hospital, Agartala, Tripura, India
}

Correspondence: Pradip Bhaumik, Assistant Professor, Department of Gastroenterology, Agartala Government Medical College President, Hepatitis Foundation of Tripura, Agartala, Tripura, India, e-mail: pradeepagt@yahoo.com

\section{ABSTRACT}

Although hepatitis B is a major public health problem globally, mass vaccination against this virus is yet to be implemented in many countries of the world, including in India, which happens to be one of the most populous nations in the globe. Hepatitis Foundation of Tripura has become a role model in combating this virus in the small north-eastern Indian state of Tripura. With infrastructural help from the Tripura Government, the foundation has done a commendable job of vaccinating 0.25 million out of 3.65 million population of the state, setting an unique example of public partnership in sustaining hepatitis $B$ virus.

Keywords: Hepatitis B, Prevention, Tripura.

\section{INTRODUCTION}

Hepatitis B virus (HBV) infection is a significant global public health problem. A total of 350 million people in the world are chronically infected by HBV and an estimated two billion people are exposed to virus in lifetime. ${ }^{1,2}$ About $78 \%$ of global pool of HBV infection is from the Asian countries, particularly the developing countries of AsiaPacific region. HBV accounts for at least $50 \%$ of the chronic hepatitis cases and 70 to $85 \%$ of hepatocellular carcinoma in this region.,

Hence, prevention of hepatitis B is of paramount importance. A vaccine against hepatitis $B$ has been available since 1982, this vaccine was plasma-derived vaccine and was not free from side effect. In 1987, recombinant DNA vaccine become available and till date this vaccine is in use worldwide. ${ }^{5}$ The vaccine has an outstanding record of safety and effectiveness. The vaccine is $95 \%$ effective in preventing HBV infection and its chronic consequences. In 1992, World Health Assembly passed a resolution to recommend global vaccination against hepatitis $\mathrm{B} .{ }^{6}$ But till date this is not uniform.

Mass vaccination program against hepatitis B has not been implemented by many countries, though it is considered that high vaccination levels in the population are necessary to decrease disease transmission and prevent disease. $^{7}$

The World's first hepatitis B virus universal vaccination program for infant was launched in Taiwan in July $1984 .^{8}$ Subsequently, Taiwan introduced mass vaccination. Since 2007, Iran's Ministry of Health carried out a nationwide hepatitis B vaccination campaign for 17-year-old adolescents. ${ }^{9}$ Alaska in USA also took a mass vaccination program. Lousiania in 1992, implemented school-based hepatitis B vaccination program. ${ }^{10}$ Hawaii took a similar program from 1996 to $1999 .{ }^{11}$ In 2009, 177 countries reported that they had included the hepatitis B vaccination into their national infant immunization program. ${ }^{6}$

Hepatitis Foundation of Tripura, a social organization with the infrastructural help from Department of Health, Government of Tripura, took a new initiative of mass hepatitis B vaccination in the small state of Tripura, in the north-eastern region of India.

\section{HEPATITIS FOUNDATION OF TRIPURA}

Tripura is a small state of north-eastern region of India having an area of 10,491 $\mathrm{km}^{2}$ and population of about 3.65 million. The hepatitis B prevalence in the state is about $4 \%$ (unpublished data). Hepatitis Foundation of Tripura took its debut on 28th July 2002. Before that, there was no awareness generation and hepatitis B vaccination program in the state. The foundation started awareness generation at the beginning and in 2003 started subsidized hepatitis B vaccination, on every Sunday using $\mathrm{MCH}$ center of government hospital. At the beginning, it was a single center at Agartala, gradually, the number of centers increased to present 31. On every Sunday, the members of foundation are performing total vaccination program completely voluntarily. In addition, round the year, there is community awareness program. The foundation also runs a regular liver clinic for detection, evaluation and treatment of hepatitis patients. 


\section{HELP FROM GOVERNMENT OF TRIPURA}

The State Health Department, Government of Tripura provides infrastructural support. The department permitted the foundation to utilize Mother and Child Health center (MCH) of all hospitals on sunday for counseling and vaccination. Health care providers of government institutions extend their help in materializing various programs. Political and administrative commitment is the boon of the initiatives of foundation. It is sort of publicprivate understanding.

\section{METHODOLOGY}

The foundation performing three-way programs:

1. Awareness generation among doctors, nurses, paramedics, students at school and colleges, people representatives and mass community people.

2. Mass hepatitis B vaccination.

3. Free liver clinic for management of hepatitis B patients.

\section{HEPATITIS B VACCINATION PROGRAM}

Hepatitis B vaccination program has some important salient features as follows:

1. Routine vaccination is done on every Sunday through 31 centers at a subsidized price.

2. Special vaccination is done through camp at a peripheral health centers with prior awareness generation program and sensitization of local leaders.

3. Monthly vaccination centers in some important places.

4. Special free vaccination program in orphanages.

5. Special program in some tribal hostels.

Hepatitis B Eradication Program: This is the most innovative program of Hepatitis Foundation of Tripura. On one single day, vaccination was done in 150 centers by the volunteers of foundation. Prior to vaccination, wide publicity was made through posturing, group meeting, community meeting, sensitization of local leaders, meeting with doctors, nurses and other health care providers. The Department of Health, Government of Tripura extended permission for this program and requested the health care providers to participate.

District administrators, engineering department, police department, social welfare department, local self Government bodies were approached and extended their help. The first such program was organized on 29th Nov 2009 and subsequent 2nd and 3rd dose vaccination was done on 3rd January 2010 and 30th May 2010. The people's participation was enormous and long queue was observed in almost all centers. Total vaccination exceeds 0.12 million. In some of the centers, vaccination could not be completed and was repeated on next Sunday. After the success of first hepatitis B eradication program, 2nd hepatitis B eradication program was organized on 21st Nov 2010 with second dose on 26th Dec 2010 and third dose on 22nd May. It was equally successful.

6. At birth, hepatitis B vaccination program is a new program of Hepatitis Foundation of Tripura. As national infant vaccination program not yet initiated, foundation started free at birth vaccination program in all hospital and health centers wherever delivery facilities is available.

7. Police vaccination: Vaccination of police personal is another successful program.

\section{RESULT}

The multiapproach hepatitis B vaccination has given a tremendous success to Hepatitis Foundation of Tripura. The output of these entire vaccination programs over the years is as follows:

\begin{tabular}{lcccccccr}
\multicolumn{8}{c}{ Vaccination in regular clinics and camps } \\
$2003-04$ & $2004-05$ & $2005-06$ & $2006-07$ & $2007-08$ & $2008-09$ & $2009-10$ & $2010-11$ & Total \\
7390 & 29870 & 58181 & 47708 & 53804 & 68146 & 85747 & 95404 & 446250 \\
\hline
\end{tabular}

Vaccination during Hepatitis B Eradication Program

\begin{tabular}{lccc} 
& Children (up to 10 yrs) & Adult (10 yr+) & Total \\
\hline 1st Hepatitis B Eradication Program: 2009-10 & 56436 & 64635 & 121071 \\
2nd Hepatitis B Eradication Program: 2010-11 & 62366 & 69124 & 131490 \\
\hline Grand total: & & 252561 \\
\hline
\end{tabular}

Total vaccination: 698811

Total percentage of population vaccinated: $19.41 \%$ 


\section{DISCUSSION}

Hepatitis B vaccination is the best way to prevent hepatitis B disease as well as chronic liver disease, liver cirrhosis and hepatocellular carcinoma (leading to death) as hepatitis B is the major cause of these disorders. ${ }^{3,4}$ Infants vaccination has been initiated in 177 countries by $2009^{6}$ but India is not in this list. Adolescent vaccination is now targeted in many counties with good success. ${ }^{12,13}$ Taiwan took exceptional strategy of mass vaccination which has reduced hepatitis B prevalence from $15 \%$ to less than $1 \% .{ }^{14}$ But available resources do not reveal any evidence of hepatitis B vaccination involving all age groups of people. Hepatitis B prevention strategy is usually taken by the government. Hepatitis Foundation of Tripura took exceptional initiative to vaccinate all groups of people. It has been observed that for hepatitis B vaccination program, mass awareness generation is a precondition. Similarly, increase in detection and treatment of patients reduces the possibility of transmission.

Screening of all pregnant mothers during pregnancy and subsequently HBIG inoculation with hepatitis B vaccination at birth to the child of positive mothers reduces the possibility of mother to child transmission. Voluntary approach by social organization reduces the possibility of defaulters in 2nd and 3rd dose due to passionate counseling. This also reduces the economic burden.

\section{CONCLUSION}

A universal hepatitis B vaccination program would provide the most immediate health benefits and acceleration toward the eradication of hepatitis B. ${ }^{12}$ Southeast Asian countries being the biggest reservoir of hepatitis B infection should immediately proceed for universal hepatitis B vaccination program. The success of such program depends upon awareness generation as well as political and administrative commitment. Media coverage and media campaign approach help the increased outcome and increments in vaccination. Constant performance monitoring gives thrust to the program. Persistent evaluation of activities and adoption of newer methodology can provide extensive success and will help in achieving $100 \%$ vaccination. This program demonstrates that mass hepatitis B vaccination is feasible and it provides practical strategy for other states of the country and other countries of Southeast Asia.

\section{ACKNOWLEDGMENT}

Hepatitis Foundation of Tripura gratefully acknowledges the generous help extended by Bristol Myers Squibb Foundation, USA, in materializing many of its programs.

\section{REFERENCES}

1. Lee WM. Hepatitis B virus infection. N Engl J Med 1997;337: 1733-45.

2. Lok AS, Heathcote EJ, Hoofnagle JH. Management of hepatitis B: 2000 — summary of a workshop. Gastroenterology 2001;120:1828-53.

3. Levanchy D. Public health measures in the control of viral hepatitis: A World Health Organization prospective for the next millennium. J Gestroenterol Hepatol 2002;17(S4):S452-S59.

4. Kane M, Clements J, Hu D. Disease control priorities in developing countries. In: Jamison DT, Mosley WH, Measham AR, Bobadilla J (Eds). New York, Oxford University Press 1993:330.

5. Harison's principles of internal medicine (17th ed). Mc Grew Hill Medical; 1932-49.

6. http://www.who.int/immunization/topics/hepatitis_b/en/ index.html

7. MMWR CDC Surveil Summ 22 Sep 2000;49(9):1-26.

8. Ni YH, Chen DS. Hepatitis B vaccination in children: The Taiwan Experience. Pathol Biol (Paris) Aug 2010;58(4): 296-300.

9. Alvain SM, Zamiri N, Gooya MM, Tehrani A, Heydari ST, Lankarani KB. Hepatitis B vaccination of adolescents: A report on the national program in Iran. J Public Health Policy Dec 2010;31(4):478-93.

10. Cassidy W. School-based adolescent hepatitis B immunization programs in the United States: Strategies and successes. Pediatr Infect Dis J July 1988;17(7S):S43-46.

11. Dilraj A, Strait-Jones J, Nagao M, Cui K, Terrell-Perica S, Effler PV. A statewide Hepatitis B Vaccination Program for school children in Hawaii: Vaccination series completion and participation rates over consecutive school years. Public Health Rep Mar-Apr 2003;118(2):127-33.

12. Lawrence $\mathrm{MH}$, Goldstein MA. Hepatitis B immunization in adolescents. J Adolesc Health Oct 1995;17(4):234-43.

13. Reece SM. Immunization strategies for the elimination of hepatitis B. Nurse Pract Feb 1993;18(2):42-45,49-50.

14. Chen DS, Hsu HM, Bennet CL, Pajeau TS, Blumberg B, Chang PY, et al. A program for eradication of hepatitis B from Taiwan by a 10 -year, four-dose vaccination program. Cancer Causes Control May 1996;7(3): 305-11. 